\title{
Psicologia e Análise de Implementação de Políticas Públicas: Um Diálogo Interdisciplinar
}

\author{
Psychology And Analysis Of Public Policy \\ Implementation: An Interdisciplinary Dialogue \\ Psicología Y Análisis De Implementación De Políticas \\ Públicas: Un Diálogo Interdisciplinario
}
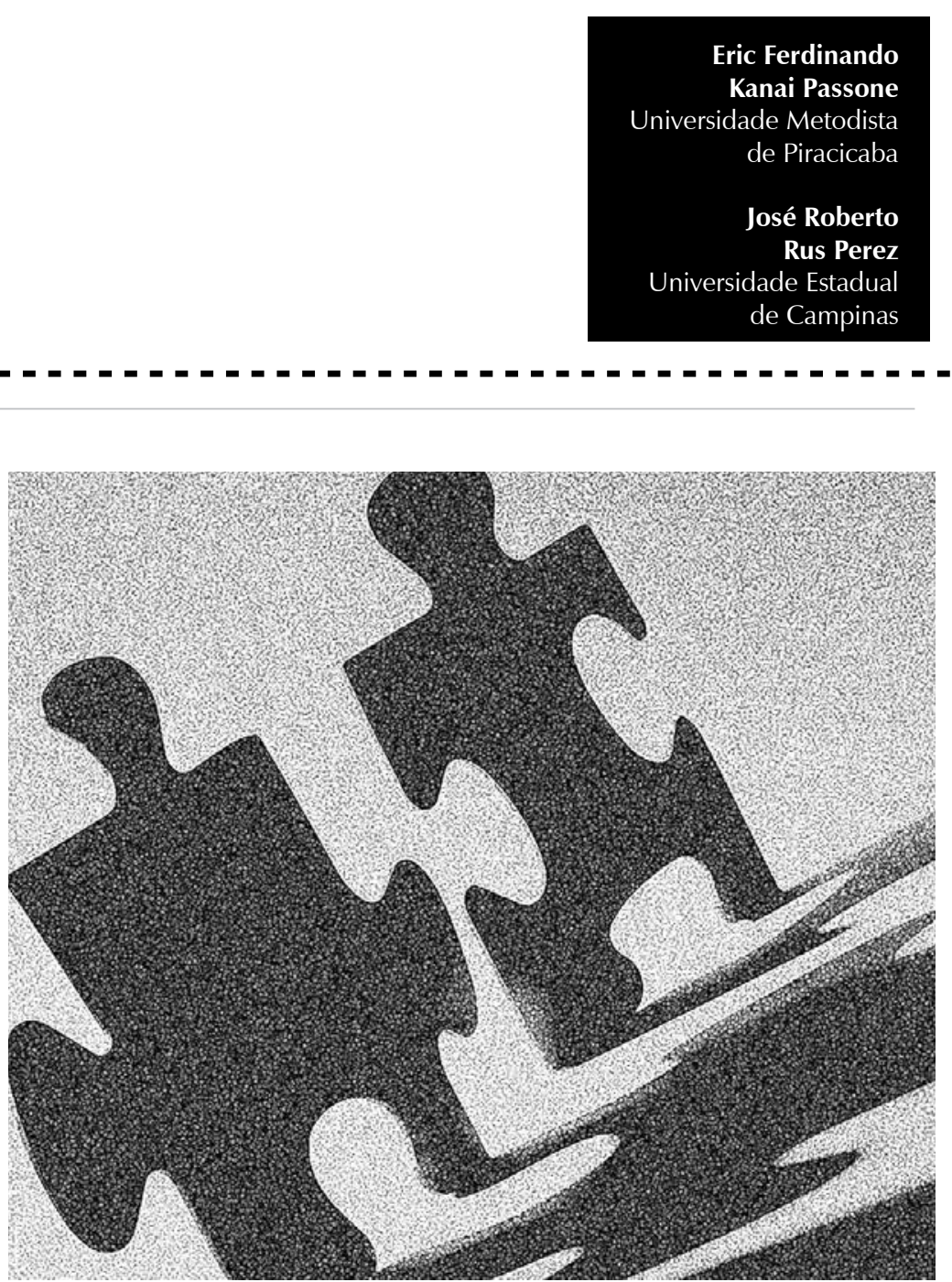
Resumo: O presente ensaio resulta da apresentação do tema Metodologias de análise de implementação de políticas públicas, no I Seminário Regional de Psicologia e Políticas Públicas, realizado pelo Conselho Regional do Rio de Janeiro, e visa a aprofundar a interlocução da Psicologia com a construção das políticas sociais a partir de uma revisão teórica sobre o campo de análise de implementação de políticas públicas. Apoiando-se na constatação do crescente interesse e da participação da Psicologia no campo das políticas públicas, discute-se o padrão de intervenção do Estado dentro do processo histórico de consolidação do sistema de proteção social no Brasil.

Palavras-chave: Democracia. Política social. Psicologia. Política de saúde.

Abstract: This paper is based on the presentation "The methodologies for public policy implementation analysis "in the I Psychology and Public Policy Regional Seminar conducted by the Rio de Janeiro Regional Council, and it seeks to deepen the dialogue of psychology with the construction of social policies, presenting a theoretical analysis on the field of public policy implementation. From the increasing interest and psychological involvement in public policies, the paper discusses the state intervention pattern in the historical social protection consolidation process in Brazil.

Keywords: Democracy. Social policy. Psychology. Helath policy.

Resumen: El presente ensayo resulta de la presentación del tema "Metodologías de análisis de implementación de políticas públicas", en el I Seminario Regional de Psicología y Políticas Públicas, realizado por el Consejo Regional de Rio de Janeiro, y tiene la intención de profundizar la interlocución de la Psicología con la construcción de las políticas sociales, a partir de una revisión teórica sobre el campo de análisis de implementación de políticas públicas. Apoyándose en la constatación del creciente interés y de la participación de la Psicología, en el campo de las políticas públicas, se discute el estándar de intervención del Estado dentro del proceso histórico de consolidación del sistema de protección social en el Brasil.

Palabras clave: Democracia. Política social. Psicología. Política de la salud.

Constata-se, nas últimas décadas, o aumento de atenção dos pesquisadores e dos estudiosos às práticas profissionais da Psicologia relacionadas à elaboração e à implementação das políticas públicas e sociais. A consolidação e a expansão dos sistemas de proteção social no Brasil, concomitantemente com o processo de construção democrática do Estado e da sociedade brasileira, remetemnos, certamente, ao percurso histórico do pensamento psicossociológico com relação aos desdobramentos históricos da política nacional.

Pode-se afirmar que tal trajetória se caracterizou por um posicionamento éticopolítico dos pesquisadores e dos profissionais implicados com as práticas sociais e comunitárias de então, que se desdobraria no estabelecimento de uma nova identidade para a Psicologia brasileira, a saber, a constituição de uma "Psicologia crítica, histórica e comprometida com a realidade social de nosso país" (Freitas, 2000, p. 170), orientada pela compreensão dos fenômenos oriundos do contexto social e histórico pautado pela práxis, com intervenções destinadas à transformação social dessa mesma realidade.

Como consequência direta, assistiu-se à institucionalização de práticas sociais diversas no âmbito da Psicologia, que possibilitaram o desenvolvimento de novos espaços de atuação bem como o acolhimento de novas temáticas (cotidiano, grupos, instituições, organizações, movimentos sociais, gênero, identidade, políticas sociais etc.), de novos campos de intervenção, além da constituição de categorias de análises e de um referencial teórico consubstanciado no materialismo histórico. A afirmação "toda psicologia é social" sintetiza a imprescindível noção de que a sociedade e as condições políticas, econômicas e culturais possuem no campo da Psicologia, não no sentido de reduzir as especificidades conceituais de cada área de sua atuação, mas de demarcar, a partir de cada especificidade, a natureza histórico-social do ser humano (Lane, 1984).Nesse sentido, 
1 O Crepop foi criado em 2006 e "configura-se como um Centro de Pesquisas e está formado em rede composta por 20 unidades locais, a partir dos respectivos Conselhos Regionais (CRP)". Sua proposta consiste em atuar na produção de referências para atuação do profissional de Psicologia em políticas públicas. Atualmente possui um número considerável de publicações e pesquisas disponíveis, na web, por meio do endereço eletrônico www. crepop.pol.org.br. verifica-se a articulação existente entre teoria e prática, entre pesquisa e intervenção da Psicologia com relação os grupos sociais assistidos por instituições públicas, sejam essas estatais, organizações da sociedade civil ou entidades públicas não estatais, no atendimento e na execução de políticas públicas. Observa-se, também, a crescente inserção institucionalizada do psicólogo em setores específicos das políticas públicas, tais como saúde, educação, assistência social, Justiça e segurança, assim como a participação efetiva dos Conselhos Federal e Regionais de Psicologia em questões sociopolíticas, nos âmbitos municipal, estadual e nacional, referentes a diversos setores: mobilidade urbana, mídia, comunicação, segurança, Justiça, direitos humanos, bem-estar social, etc. O Conselho Federal de Psicologia, por exemplo, tem fomentado ações específicas nessa área, por meio do Centro de Referência Técnica em Psicologia e Políticas Públicas (CREPOP ${ }^{1}$ ), que busca conhecer e pesquisar a realidade das práticas profissionais dos psicólogos, produzindo conhecimento sobre essas práticas e socializando importantes conteúdos e reflexões à práxis psicológica no campo das políticas públicas. De acordo com Gonçalves,

Na saúde, na educação, na assistência social, em áreas da defesa civil, de habitação, os psicólogos são chamados para compor as equipes que vão efetivar e implementar políticas sociais. Esse campo se amplia e fica cada vez mais facilmente reconhecido. Com isso, o debate da inserção da Psicologia no campo das políticas públicas reconhece que o psicólogo pode estar nos vários níveis das políticas. Isso significa estar desde a formulação de programas até a sua execução propriamente dita, sua avaliação, e também na relação com os espaços de controle social, trabalhando para que haja uma compreensão das políticas públicas como espaços de garantias de direitos nesse cenário (2011, pp. 62-63)
Paralelamente, e consonante com seu tempo, a Psicologia tem incorporado novos temas emergentes da realidade sociopolítica da sociedade brasileira, tais como os mecanismos de participação e controle social, as políticas públicas e sociais e os direitos humanos, visando ao fortalecimento da cidadania e à ampliação de espaços cada vez mais públicos, ampliando as formas de participação da sociedade junto ao Estado (Gonçalves, 2010; Sass, 2007; Saadallah, 2007).

Considerando a atuação da Psicologia junto às políticas públicas e a importância de fortalecer a interlocução entre essas áreas, apresentamos, neste texto: (i) uma contextualização histórica sobre o padrão político cultural e institucional de intervenção do Estado, apresentando características do Estado no atendimento aos direitos sociais e à cidadania, bem como as mudanças e as transformações ocorridas a partir do contexto de democratização societária, do contexto de reforma administrativa do Estado e de neoliberalismo, (ii) uma breve revisão teórica dos estudos de implementação de políticas públicas - estudos que consideramos contribuições importantes e que podem nos ajudar a discutir a atuação ético-político da Psicologia com relação à consolidação e à implementação das políticas públicas e sociais no País, e, por último, (iii) algumas considerações sobre a importância da participação e do envolvimento dos profissionais e dos estudiosos da área da Psicologia na construção das políticas sociais, bem como a importância dos saberes e das práticas da Psicologia para a elaboração e a implementação de políticas públicas, apontando como a Psicologia tem contribuído para a implementação de políticas públicas, a partir de sua atuação por meio de diversas formas de ação e atividades, no campo das políticas. 
Raimundo Faoro (2001) auxilianos, também, a revelar de forma contundente as raízes dos interesses privados na formação do poder político brasileiro. Essa característica, que remete à fatídica herança do colonialismo e do patrimonialismo, é marca do domínio do poder político sob a predominância do fator econômico e dos interesses privados.

\section{Estado, direitos sociais e cidadania}

Iniciamos apresentando um recorte específico sobre o padrão de intervenção do Estado, relacionando-o tanto com o reconhecimento dos direitos constitutivos da cidadania quanto com o processo histórico de emergência e de consolidação do sistema de proteção social brasileiro. Tal recorte incide sobre dilemas contemporâneos que transpassam o debate sobre a democratização societária e institucional, a participação da sociedade civil e a própria noção de cidadania, objetivandose por meio das relações historicamente constituídas entre as pessoas, no nível de atendimento às políticas públicas.

A indissolubilidade entre cultura e política, sendo a primeira compreendida como a produção e a circulação de significados e de representações constitutivas de toda prática humana, e a segunda, como um terreno marcado por relações de poder e força, conflitos, lutas e interesses, deve ser considerada em qualquer análise das práticas sociais que consolidaram as sociedades democráticas pós-industriais. No Brasil, o processo de construção democrática envolve contradições e ambiguidades históricas, tanto na perspectiva cultural e política quanto na perspectiva institucional. Tais contradições, uma vez reveladas e refletidas, auxiliam-nos a compreender a importância da função mediadora das práticas sociais no campo das políticas públicas. Isso implica fazer um breve retorno à história do desenvolvimento político do Estado brasileiro, sua relação com a oferta de políticas sociais e o reconhecimento dos direitos de cidadania.

Historicamente, tal processo se caracterizou pelo autoritarismo de diversos governos, pela indistinção entre o mundo público e o mundo privado, pelo forte traço do patrimonialismo econômico e político, marcado pelo clientelismo e pelo paternalismo populista, e pela presença de um poder excessivo do Executivo em detrimento do Legislativo e do Judiciário. O historiador José Murilo de Carvalho (2004) denominou "estadania" a prevalência de uma relação unilateral e direta que se estabeleceu entre o Estado e o indivíduo, no qual o primeiro está representado como um ente "todo poderoso", que ora "reprime e cobra impostos", ora se apresenta como um "distribuidor paternal de benefícios, empregos e favores", gerando uma relação Estado-sociedade que sempre supervalorizou o Poder Executivo e, em consequência, suas formas tradicionais de cooptação e de regulação social da organização societária.

Raimundo Faoro (2001) auxilia-nos, também, a revelar de forma contundente as raízes dos interesses privados na formação do poder político brasileiro. Essa característica, que remete à fatídica herança do colonialismo e do patrimonialismo, é marca do domínio do poder político sob a predominância do fator econômico e dos interesses privados. Os "donos do poder" ou o "patronato político brasileiro" representam, historicamente, as elites regionais dominantes cujo poder econômico se apropria dos sistemas políticos.

No início da República, o patrimonialismo era garantido pela cultura da cordialidade, resquício das relações escravagistas, pela relação de clientelismo existente entre o senhor das terras e seus subordinados e pelo violento sistema do voto do cabresto, característico das disputas eleitorais da época. Como herança histórica, o patrimonialismo se expressa, na cultura política brasileira, como a influência do poder econômico na determinação eleitoral e, principalmente, na indissociabilidade entre o mundo público e o mundo privado.

Na perspectiva institucional, trata-se de 
reconhecer o desenvolvimento do arcabouço sociojurídico, que regula o processo social e político de organização da sociedade. Nesse caso, os estudos de políticas públicas constatam que, entre o período de 1930 e 1980, ocorreu a introdução, a expansão e a consolidação jurídico-social dos mecanismos de garantia social e de subvenção de renda, como a previdência social e a assistência, a construção de uma rede de ensino básico e científico, a política de atenção à saúde e a política habitacional (Nepp, 1991). Também é relevante destacar que os três maiores momentos de transformações institucionais e de produção de legislação social estiveram associados às três profundas alterações que envolveram o Estado brasileiro no século XX, a saber, o Estado Novo, caracterizado pelo autoritarismo populista de Getúlio Vargas (1930-1945), a ditadura militar (1964-1985) e o período de redemocratização, a partir de 1985 (Carvalho, 2004; Nepp, 1991).

Verifica-se, assim, que o desenvolvimento do arcabouço de proteção social manteve estreitas relações com os períodos autoritários (Estado Novo e o regime militar), limitandose a regulação social pela via da força e pela cooptação ideológica das forças trabalhadoras por meio da concessão pontual de direitos sociais e políticos para certos estratos sociais. Essa concessão de direitos ocorreu por meio da incorporação gradativa de segmentos sociais ao sistema de proteção social em detrimento do reconhecimento e da garantia dos direitos civis, políticos e sociais à sociedade em geral. Paralelamente, os momentos históricos de totalitarismo e a elaboração crítica de tais sistemas permitiram que se explicitasse um programa de ação para combatê-los: "Se há algo importante a fazer em termos de consolidação democrática, é reforçar a organização da sociedade para dar embasamento social ao político, isto é, para democratizar o poder" (Carvalho, 2004, p.227). Essa visão destina-se a combater o autoritarismo social antidemocrático, por um lado, e a promover uma cultura política destinada à socialização do poder político do Estado, por outro. Segundo Carvalho, "a organização da sociedade não precisa e não deve ser feita contra o Estado em si. Ela deve ser feita contra o Estado clientelista, corporativo, colonizado" por interesses particulares (2004, p. 227).

Na área de análises de políticas sociais e de estudos comparados de sistemas de proteção social, os trabalhos de King (1988) apontam quatro grupos de fatores ou padrões explicativos sobre a origem e o desenvolvimento do Estado de bemestar moderno no mundo. O primeiro caracteriza-se pela explicação causal que relaciona a emergência dos welfare states com os efeitos diretos do desenvolvimento da industrialização e da economia capitalista. Tais efeitos retratam toda a dimensão de controle exercido pelo Estado sobre o indivíduo e a legitimação da reprodução social dentro do sistema capitalista. O segundo grupo de fatores explora a difusão de valores liberais (liberdade, igualdade e solidariedade) atrelados ao avanço da democracia e associados à expansão dos mercados. Nesse caso, o reconhecimento dos direitos sociais pelo Estado também está relacionado ao avanço econômico, do qual dependeria a reprodução das sociedades modernas, cujo próprio modelo de produção econômica garantiria um mínimo social básico para a sobrevivência da sociedade capitalista. Um terceiro padrão explicativo, situado na vertente histórico-crítica, sustenta como causa primária a mobilização da força trabalhadora, no sentido de articular demandas por direitos políticos e sociais junto ao Estado. Por último, uma análise neoinstitucional pautada no modelo burocrático sustenta que a expansão do Estado de bem-estar pode ser compreendida pelo viés dos interesses dos funcionários públicos em resguardar sua área de atuação por meio de ações corporativas bem definidas. Orloff e Skocpol (1984) 
argumentam que os dois primeiros grupos causais se relacionam com a consolidação inicial das políticas do welfare state, enquanto os dois últimos se relacionam com a sua subsequente expansão.

No Brasil, se é que podemos de fato falar na existência de um welfare, o desenvolvimento e a consolidação do sistema de proteção social foram marcados por um tipo específico de Estado de bem-estar social, cujo funcionamento se caracterizou pelo tipo "meritocrático-particularista" e/ou "modelo conservador" (Draibe, 1995, p. 201), segundo a classificação proposta por Esping-Anderson (1985), o que o difere tanto de um modelo residual ou liberal quanto de um padrão institucional-redistributivista ou social-democrata. Conforme Medeiros (2001), "tipos meritocráticos-particularistas tendem, no limite, a reforçar as desigualdades preexistentes", servindo de mecanismos de "estratificação social", uma vez que as políticas sociais não são concebidas para todos, inscrevendo-se, assim, como modelo particularista de Estado de bem-estar ou de Estado-providência.

Esse dispositivo político de regulação social, proposto por Santos, ficou conhecido pela noção de cidadania regulada, sendo esta entendida como "o conceito de cidadania cujas raízes se encontram não em um código de valores políticos, mas em um sistema de estratificação ocupacional no qual os direitos do cidadão se restringem aos direitos que ele ocupa no processo produtivo, tal como reconhecido por lei..." (Santos, 1989, p. 68). Enfim, a cidadania regulada representou o privilégio de alguns grupos de trabalhadores em detrimento dos direitos da população como um todo, característica marcante da cultura política no Estado novo.

De modo diverso, nos países centrais da Europa, a ampliação progressiva de direitos (civis, políticos e sociais) foi preponderantemente de ordem política, envolvendo amplamente a participação civil, sendo esta fortemente alicerçada no reconhecimento das liberdades civis e individuais. O trabalho de T. H. Marshall (1967), Cidadania e Classe Social, que expressa tal pensamento, considera o surgimento das políticas igualitárias do século XX em função da ampliação progressiva dos direitos civis, no século XVIII, dos direitos políticos, no século XIX, e, dos direitos sociais, no século XX. Para Marshall, a cidadania é composta por três dimensões ou três direitos: os civis (relacionados às liberdades individuais, como o direito de ir e vir e os direitos relacionados aos trabalhadores), os políticos (relacionados ao direito de organização política e de participação do povo no exercício do poder político), e, finalmente, os sociais (associados à participação individual e coletiva na riqueza socialmente produzida).

Historicamente, tais direitos evoluíram de acordo com os níveis de mobilização e de organização social, fatores que explicam as diferenças no desenvolvimento dos direitos que compõem a noção de cidadania, entre distintos países. De modo comparado, pode-se dizer que, no Brasil, o processo de constituição dos direitos de cidadania ocorreu de forma invertida, ou seja, os direitos sociais precederam a conquista dos direitos civis e políticos, implicando a formação de uma cidadania ao avesso, na qual a relação entre indivíduo, grupos e organizações com o Estado retrataram uma espécie de negociação direta entre ambos, sem passar por mecanismos de representação política e democrática, caracterizada pela dependência passiva - paternalista, populista, assistencialista e clientelista. Segundo Carvalho, "primeiro vieram os direitos sociais, implantados em período de supressão dos direitos políticos e de redução dos direitos civis", no período do populismo autoritário da era Vargas. E continua: "a maior expansão do direito do voto deu-se em outro período ditatorial, em 


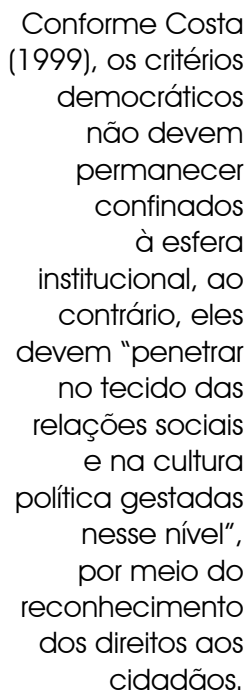

que os órgãos de representação política foram transformados em peça decorativa do regime" (2004, p. 219).

Tal contexto histórico implica, necessariamente, o reconhecimento da base frágil da cultura de direitos presentes nas práticas das políticas brasileiras relacionadas ao reconhecimento do outro como portador e sujeito de direitos civis, políticos e sociais. A mesma inversão da sequência de direitos reforçou o poder e o papel predominante do Estado, na cultura política brasileira, como ente que concede ou nega a condição de cidadão aos indivíduos. Sabe-se, também, que a construção democrática tem disposto três projetos políticos distintos, a saber, os projetos autoritário, (neo)liberal e democrático-participativo, que colocam suas respectivas tendências políticas em disputa, na sociedade civil, na burocracia estatal e no espaço público, visando ao consentimento social e à conquista do poder (Dagnino, 2004; Nogueira, 2004). Logo, a luta pela democratização concretiza-se por meio desses antagonismos, que retratam os conflitos entre os distintos projetos de hegemonia subjacentes à sociedade civil e política brasileira, transpassando grupos, organizações e instituições, bem como o saber (conhecimento), o saber-fazer (técnico) e o saber ser (ético-político) dos profissionais implicados em tais dimensões.

A conquista dos direitos de cidadania e a institucionalização da participação política e social, condições imprescindíveis à organização democrática da sociedade brasileira, consolidaram-se na Constituição de 1988, as quais têm possibilitado, desde então, a criação e o fortalecimento de mecanismos de interlocução e de cogestão entre o Estado e Sociedade em todos os níveis e setores, tais como os conselhos setoriais de políticas públicas, os fundos públicos, os orçamentos participativos, os serviços de ouvidoria, defensoria pública, etc. (Gecd,
1999; Dagnino, Olvera, \& Panfichi, 2006) e a mudança do padrão de políticas sociais.

Assim, a partir da regulamentação da Constituição da República Federativa do Brasil, em outubro de 1988, constituíramse as principais legislações com base nos direitos sociais: o Estatuto da Criança e do Adolescente (Brasil, 1990), a Lei Orgânica da Saúde - LOS (Lei Federal no. 8.080/90), a criação do Conselho Nacional dos Direitos da Criança e do Adolescente CONANDA (Lei Federal no. 8.242/91), a Lei Orgânica da Assistência Social - LOAS (Lei Federal no. 8.742/93), a Lei de Diretrizes e Bases da Educação Nacional - LDBEN (Lei Federal no. 9.394/96), a Lei Orgânica de Segurança Alimentar - LOSAN (Lei Federal no. 11.346/06), além da recente integração dos serviços sociais, por meio do Sistema Único de Assistência Social - SUAS (Perez \& Passone, 2010).

Entretanto, a organização social democrática implica o reconhecimento dos valores democráticos no âmbito relacional das práticas sociais. Conforme Costa (1999), os critérios democráticos não devem permanecer confinados à esfera institucional, ao contrário, eles devem "penetrar no tecido das relações sociais e na cultura política gestadas nesse nível", por meio do reconhecimento dos direitos aos cidadãos. Nesse sentido, o binômio Estado-sociedade necessita garantir condições de reconhecimento dos indivíduos como sujeitos e portadores de direitos, proporcionando-lhes a incorporação de elementos ético-políticos constituintes da organização democrática da sociedade.

As diversas formas de organização da sociedade civil e a criação de espaços públicos de participação política e social potencializaram a valorização e/ou reconhecimento do outro como sujeito e portador de direitos, contribuindo para a consolidação de espaços para aprendizagem 
de uma cultura de direitos (Gecd, 1999). A consolidação de tais mecanismos também depende da promoção e da qualificação das organizações sociais, no sentido de gerir coletivamente a construção de regras e de parâmetros públicos e de propor procedimentos destinados ao acompanhamento e à avaliação das políticas públicas, que acentuem a reinvenção de um Estado ético-político para a sociedade civil (Nogueira, 2003; 2004).

O fortalecimento das organizações da sociedade civil e a discussão sobre a atuação de novos atores sociais no cenário de atendimento às políticas sociais têm desempenhado a importante função de iluminar o caráter heterogêneo da sociedade civil como espaço de disputas de interesses, principalmente em relação ao Estado e aos recursos destinados a essas políticas. Isso reforça a importância da redefinição dos limites entre o interesse público e o privado bem como a tentativa de constituir uma esfera pública com qualidade ético-política, capaz de repor e de pactuar socialmente projetos políticos com a sociedade civil e política, embasados na relação de direitos civis, políticos e sociais e no combate aos projetos políticos autoritários e/ou a formas privatizadas de poder.

Nesse cenário, a Psicologia enfrenta o desafio de qualificar o seu profissional no que se refere à atuação em políticas públicas, de criar referências para as suas práticas, de forma a incluir a perspectiva socio-histórica de ciência e análise de tais ações e a garantir o património histórico da cidadania, representado pelos nossos direitos civis, políticos e sociais, combatendo discursos, organizações e práticas regressivas e autoritárias de controle e poder.

Gonçalvez lembra-nos que "a necessidade de nos debruçarmos sobre a própria prática da profissão, pensando em seu fazer político, em seu lugar social, em suas possibilidades de inserção. Nesse sentido, temos reconhecido a necessidade de a Psicologia se colocar, frente à sociedade, em defesa dos direitos sociais, dos direitos humanos" (2011, p.61). Isso representa, também, o desafio de pensar sobre a construção de um trabalho interdisciplinar, multiprofissional que englobe as políticas públicas no campo da Psicologia, ao mesmo tempo em que, indiretamente, desloque a visão elitista e privatizada da Psicologia como uma tecnologia sobre a subjetividade do indivíduo no particular para um olhar mais social e coletivo, que considera o sujeito que faz laço no e pelo social, situado em uma rede de discursos e de condições históricas que, ao mesmo tempo, o constitui e determina suas objetivações frente ao real da política, ou seja, também determina ao sujeito sua posição subjetiva com relação a sua realidade, a sua sociedade e a sua identidade, tornando possível criar novas possibilidades históricas. Mais do que isso, o compromisso e a responsabilidade ética e política da Psicologia tendem à superação das dicotomias indivíduo-sociedade, internoexterno, para "trabalhar com a noção de dimensão subjetiva dos fenômenos sociais", noção fundamentada na dialética subjetividade-objetividade, de acordo com o que afirma Gonçalves:

...considerar a dimensão subjetiva dos fenômenos sociais presentes no campo das políticas públicas permite que as políticas considerem o sujeito a que se destinam e, ao mesmo tempo, apontem o campo social em que se propõem a introduzir transformações, dirigidas aos objetivos das referidas políticas. (...) A atuação em políticas públicas deveria revelar compromisso com o cidadão, com o ser humano, em outras palavras, um projeto político. Um projeto político voltado ao resgate da cidadania e garantindo participação popular (2010, pp. 116-17)

Como dito anteriormente, o processo de democratização societária não é apenas um mero momento de transição do 
sistema político, mas sim, um processo permanente de concretização da soberania popular, conjuntamente à garantia e ao desenvolvimento de instituições democráticas, tais como as eleições livres, o sufrágio universal, o parlamento ativo, a liberdade de imprensa, etc. A existência da democracia implica a incorporação dos valores democráticos nas práticas cotidianas, pois a construção democrática passa pelo reconhecimento dos direitos de cidadania como vetor axiológico das relações sociais, através de suas interações sociais, em que cada sujeito passa a ser reconhecido e identificado como portador de direitos e deveres, o que confere estofo a sua identidade, ou status de ter direito a ter direitos.

\section{Democratização, políticas públicas e reforma de Estado}

O período de redemocratização do Estado brasileiro caracterizou-se pela descentralização, municipalização de políticas e institucionalização da participação social e do controle social, com a criação de conselhos de políticas públicas como espaços de interlocução e de cogestão política entre a sociedade e o Estado. No plano políticoeconômico, a reforma administrativa do Estado, em meados da década de 90, teve o objetivo de conciliar, por um lado, o crescimento econômico, e, por outro, as demandas por uma democracia social, no cenário de escassez de recursos públicos e de tendências neoliberais de redução estatal. Em decorrência, a estratégia de constituição de um sistema de proteção social se baseou nos modelos tradicionais de programas destinados à transferência monetária contemplando famílias em vulnerabilidade social, ou seja, por intermédio de políticas sociais compensatórias e complementares, objetivando-se o aumento do acesso à alimentação, à saúde e à educação básica como fatores de grande potencial para a redução das desigualdades e da competitividade econômica (Draibe, 1997).

Houve, também, uma demanda expressiva de políticas sociais, em favor da justiça e da equidade social, do combate à pobreza e às desigualdades sociais. No entanto, as políticas sociais brasileiras caracterizamse mais pela focalização e seletividade de sua cobertura, com o avanço universal em algumas áreas (como saúde e educação), pela luta por redução do estatismo, mas com preservação do caráter público e gratuito dos serviços, pelo aprofundamento da articulação com organizações sociais e com o setor privado, e pelo discurso político homogêneo com relação à defesa dos programas de transferência monetária direta, como os de renda mínima e combate à pobreza.

No que concerne aos pontos centrais de efetivação da nova agenda e das diretrizes de reorganização do sistema de políticas sociais, a descentralização dos programas, a mercantilização das políticas sociais, a conjugação de esforços públicos e privados (parcerias, organizações civis e empresariais), a integração de programas e o resgate das sinergias sistêmicas têm sido os alicerces do reordenamento institucional, sendo o gasto público social moldado pelo modelo gerencial de desenvolvimento humano sustentável, destinado a elevar seu padrão de eficácia e eficiência como investimento no campo social (Draibe, 1995, 1997).

Uma outra diretriz desse processo de reestruturação em direção à economia competitiva globalizada pressupôs a integração de programas e o resgate das sinergias sistêmicas como ajustes necessários para as políticas e os investimentos sociais. Nesse sentido, a reorganização das políticas sociais consistiria na integração de objetivos e de estratégias de ação frente a um dado público-alvo, junto à noção de complementaridade que envolvesse o Estado, 
Como agravante,

tais mudanças no padrão de atendimento dos serviços sociais coexistem à sombra de antigas práticas caritativas e benevolentes,

que antecederam a atual noção de direito a ter direito, e que, normalmente, se pautavam em ações de caráter assistencialista e clientelista, e não eram concebidas para o exercício e o reconhecimento dos direitos civis e sociais de cidadania (Perez \& Passone, 2010). a iniciativa privada (mercado) e a sociedade. Tais iniciativas seriam implementadas junto ao processo de reorganização dos serviços públicos, principalmente dos programas sociais, e poderiam ser consideradas uma das metas gerais da reforma do Estado.

No término da macrorreforma administrativa, multiplicou-se o espaço contratual de prestação de serviços na área social, bem como institucionalizaram-se os mecanismos de participação social nas decisões de políticas públicas, o que, de certa maneira, deslocou os movimentos sociais de suas formas tradicionais de atuação, canalizandoos para ações menos contestatórias, como as ongs, as organizações sociais, além das ações assistenciais tradicionais (Dagnino et al., 2006). Como agravante, tais mudanças no padrão de atendimento dos serviços sociais coexistem à sombra de antigas práticas caritativas e benevolentes, que antecederam a atual noção de direito a ter direito, e que, normalmente, se pautavam em ações de caráter assistencialista e clientelista, e não eram concebidas para o exercício e o reconhecimento dos direitos civis e sociais de cidadania (Perez \& Passone, 2010).

$\mathrm{Na}$ atualidade, os grandes desafios do desenvolvimento social impõem-se no estabelecimento de políticas econômicas orientadas para o crescimento sustentado e não inflacionário e em políticas sociais eficazes para a promoção da equidade e do desenvolvimento humano. O cenário que se apresenta tem alertado muitos planejadores públicos para a sua relativa capacidade de decisões quanto, por um lado, à preservação de um patamar ideal (mínimo ou não) de gasto social, que gere continuidade no desenvolvimento social, e, por outro, à geração e à oferta de empregos "que se logre introduzir na economia, através de políticas públicas adequadas, de modo a preservar as bases da integração social, os novos dinamismos do crescimento" sustentável
(Draibe, 1997, p.13). Para os críticos, os novos papéis dos governos substituíram as políticas keynesianas por políticas restritivas de gastos. Desse modo, no âmbito das políticas públicas, o ajuste fiscal tem implicado a adoção de "orçamentos mais equilibrados entre receita e despesa e restrições à intervenção do Estado na economia e nas políticas sociais" (Souza, 2006, p. 20).

A criação de capacidades administrativas, nos níveis descentralizados, e a importância considerada à integração de objetivos, recursos e formas de ação frente a um dado público-alvo e/ou em torno de políticas públicas específicas, tais como as políticas sociais, são dimensões que vêm exigindo tanto a produção de informações como a capacitação dos agentes administrativos e dos atores sociais para o planejamento, o monitoramento, a avaliação e a socialização de conhecimentos sobre políticas públicas (Cohen \& Franco, 2007).

Tendo por cenário o contexto políticoeconômico, podemos lançar luzes sobre o campo de estudos de análise de implementação das políticas públicas, como discurso e forma de produção de conhecimento sistematizado sobre as políticas sociais, que passaram a ganhar prestígio a partir de 1950, nas Academias norteamericanas e europeias, e, no Brasil, no início dos anos 90 .

\section{Apontamentos teóricos sobre a implementação de políticas públicas}

O conceito de políticas públicas é polissêmico, mas existe um consenso comumente utilizado nessa área: política pública consiste nas ações que os governos decidem colocar em prática para a solução de problemas públicos. Seu objeto de análise, utilizandose o jargão acadêmico, constitui o "Estado 
em ação ${ }^{2}$ ", ou o "estudo de programas governamentais, particularmente suas condições de emergência, seus mecanismos de operação e seus prováveis impactos sobre a ordem social e econômica" (Arretche, 2003, p.8).

Para alguns autores, a implementação refere-se a todo o processo iniciado com o estabelecimento da política até o seu impacto; para outros, a implementação não se confunde com os seus efeitos (objetivos e subjetivos), sendo basicamente comparada com uma série de decisões e de ações postas pela autoridade legislativa central. Uma concepção mais delimitada da implementação distingue etapas da policy, pelo menos duas, que antecedem a implementação: a fase da formação da política, que implica a constituição da agenda, a definição do campo de interesse, e a identificação de alternativas e a fase da formulação da política, quando as várias propostas se constituem em política propriamente dita, mediante a definição de metas, objetivos, recursos e a explicitação da estratégia de implementação. Pressman e Wildavsky (1984), em trabalho seminal para a área, delimitaram o início do processo de implementação no momento em que a política é transformada em programa, isto é, quando, por ação de uma autoridade, são criadas as condições iniciais à implementação. Muitos estudiosos, porém, discutem as dificuldades de se distinguir a implementação da própria política, programa ou projeto. Lester e Goggin (1998) enfatizaram que a implementação de política pública continua a despertar um grande interesse prático para os tomadores de decisão, porque esse tipo de investigação tem proporcionado o acúmulo de conhecimento sobre os problemas e as dificuldades que impedem de se atingir os objetivos no processo da política, constituindo uma fonte importante de subsídios para os formuladores de políticas. Assim, muitos analistas políticos consideram que a pesquisa da implementação de política é uma das mais utilizadas áreas da análise de política (Perez, 2010).

Desde então, a literatura especializada tem chamado a atenção para as contribuições proporcionadas por esse tipo de pesquisa: 1) visam a corrigir o curso das ações, fornecendo subsídios aos implementadores durante o curso da política, em razão de suas características de policy oriented, 2) buscam ampliar a efetividade do processo de decisão dos programas públicos, 3) contribuem para ampliar a accountability dos programas e 4) ampliam a integração dos corpos administrativo, político e comunidade, que são fundamentais para a mudança do desempenho de uma política.

Pode-se dizer que os estudos de políticas se tornaram ferramentas imprescindíveis para os governos elaborarem políticas públicas. A pesquisa de implementação de políticas tem se beneficiado, nos últimos anos, do conjunto de ideias que derivam de quatro décadas de pesquisa, especialmente nos EUA, e constata-se que elas são adequadas a: grande grau de estabilidade política, forte tradição democrática, bases de informação acessíveis para orientar a formulação e burocracia relativamente não corrupta com forte tradição de avaliação profissional.

A avaliação de políticas, programas e projetos sociais foi incorporada, de fato, à agenda governamental brasileira no início dos anos 90. Entre os fatores que contribuíram para isso, destacam-se: a consolidação democrática, o ajuste econômico e a consequente redução dos recursos para a área social, as maiores exigências impostas pelos órgãos financiadores, especialmente internacionais, em relação ao controle de gastos e resultados, etc. Uma dinâmica de racionalização, que incluiu a observância dos critérios de eficácia, efetividade e eficiência na utilização dos recursos financeiros e uma 
preocupação crescente com a accountability, passou a envolver a gestão pública brasileira (Perez, 2010).

É interessante verificar o quanto, inicialmente, a ideia de implementação se restringia ao cumpra-se da política, uma vez que ela não era considerada no desenho desse âmbito, já que se pressupunha que a decisão de uma autoridade seria automaticamente cumprida. O mérito do estudo de Pressman e Wildavsky (1984) foi demonstrar o quanto, apesar da decisão do nível central, a operacionalização do programa apresentava inúmeros percalços no nível local.

Ao efetuarem um balanço das pesquisas, empreendidas entre 1960 e 1985, nos Estados Unidos, Lester (1987) traçou as características básicas de, pelo menos, três gerações de estudos de implementação. A primeira (1970-1975) enfocou detalhadamente os acontecimentos empreendidos por uma única instância de autoridade decisória, caracterizando-se pelos estudos de caso centrados, especialmente, na identificação dos obstáculos à implementação. A segunda geração de estudos (1975-1980) identificou os sucessos e os fracassos da implementação e desenvolveu modelos analíticos, arrolando um conjunto de fatores que contribuíam para o sucesso ou o fracasso dos objetivos da política. Essa categoria de estudos comportou duas abordagens: a primeira, designada top-down, centrada na identificação de um conjunto de variáveis formuladas a partir da decisão política da autoridade governamental central, procurava responder questões como: o grau de alcance dos objetivos da política, o equacionamento dos impactos e os objetivos, os principais fatores que afetam o impacto e a própria política e as reformulações obtidas ao longo do tempo. A segunda abordagem inclui modelos botton-up, cujos enfoques se centraram nos atores envolvidos na prestação de serviços locais, sendo relevante identificar os seus objetivos, estratégias, atividades e contatos. Os pressupostos básicos desse modelo são a compatibilidade dos programas aos desejos, vontade e padrões comportamentais dos atores e o processo de descentralização.

Linder e Peters (1987) consideram que a distinção entre os estudos botton-up e topdown sintetiza as concepções de duas escolas de estudos de implementação. A primeira é basicamente europeia e fenomenológica, e a segunda, positivista e americana. Embora ambas as abordagens detenham uma concepção instrumental da política, outras diferenças marcam tais estudos, fazendo com que a escola designada top-down evoque uma visão objetiva da política, como produto do desenvolvimento de um processo exógeno, sendo, portanto objetivamente verificável, com intenções políticas que podem ser alteradas e solucionadas.

Afora as controvérsias epistemológicas entre o objetivismo e subjetivismo contidas nessas abordagens, Linder e Peters (1987) ainda argumentavam a respeito das consequências desses modelos adotados pelos acadêmicos no sentido de limitarem o campo de possibilidades que devem ser consideradas pelos formuladores, em outras palavras, as relações entre os estudos acadêmicos e os formuladores de política.

A terceira geração de estudos integra os modelos mais dinâmicos e processuais, que pressupõem não apenas a relação da implementação com o contexto mais geral da macropolítica - o que se pode identificar como determinação externa - como também as relações dinâmicas entre as estruturas organizacionais, os distintos recursos de apoio mobilizados e as características sociais, culturais e econômicas dos atores, por serem estes agentes do processo de implementação. Esse conjunto de fatores, interagindo entre si e com a estratégia de implementação, pode 
afetar o grau de alcance dos resultados e as formas da implementação.

Em suma, no campo de implementação das políticas, quando do início das análises, havia a crença de que a elaboração de uma política bem desenhada, em sua dimensão mais formal e técnica, objetivos e estratégias de implementação claros e bem definidos e recursos humanos e financeiros disponíveis eram suficientes para alcançar as mudanças propostas, entretanto, os analistas ignoravam o dinamismo entre a política, o seu contexto e os seus atores. Esse desconhecimento foi patente em especial nos discursos do tipo top down sobre implementação de políticas educacionais, retratando o modelo racional e autoritário de elaboração de políticas impostas de cima para baixo, que pressupunha que os implementadores simplesmente agiriam e se comportariam conforme o determinado, de modo racional e orientados de acordo com objetivos, metas e planejamentos pré-estabelecidos.

Uma análise mais detalhada do processo enfatizou a importância do contexto institucional, as relações entre os distintos atores locais com o conteúdo das políticas e as dinâmicas desses processos, conforme propuseram os defensores do modelo de baixo para cima. Desse modo, a implementação passou a incluir a dimensão do implementador, transformando-o, ao mesmo tempo, em objeto de observação e de investigação dos estudos de implementação e em um ator privilegiado e imprescindível, quando se trata da execução da policy. Sua importância reside, além de tantas outras de que nos falam os discursos da implementação de políticas, no fato de esses atores serem depositários de uma demanda social de direito, talvez o primeiro, e, às vezes, o único elo possível para estabelecer algum tipo de laço social que não seja de assujeitamento, mas de reconhecimento de direitos. A questão é que a política em ação depende de pessoas e de grupos reais, das suas ideias, dos seus sentimentos e dos seus fazeres, ou seja, ela somente adquire subjetivamente sentido no ato da expriência ou da vivência de tal fenômeno social, e é preciso conhecer o sentido, a finalidade e os efeitos que a prática de uma política produz pela relação concreta que se objetiva sob os discursos que compõe o complexo e difuso campo de interesses que transpassa tantos os profissionais dos programas e projetos quanto os destinatários dessas ações. No universo acadêmico, pode-se observar certas pesquisas que demonstram a importância de se considerar a singularidade que uma política assume quando da sua implementação, reforçando a tendência atual de se levar em conta a dimensão subjetiva, os atores e as condições estruturais que delimitam a complexidade de tal processo (Hill, 2006).

No nosso entender, os estudos botton up representaram a inclusão da dimensão subjetiva, quando considerada a operacionalização de uma política, dimensão essa que confere relevância à linguagem e aos discursos no processo de elaboração e de implementação de políticas (Passone, 2012). Esse modelo está alinhado ao planejamento socializado ascendente, como exemplo, bem como ao planejamento participativo, que admitem modelos de cogestão e de participação dos envolvidos nas tomadas de decisão, na proposição de ações conjuntas e no controle e avaliação dos programas, projetos e políticas.

\section{Considerações finais}

Em contextos complexos como os das cidades brasileiras, as políticas públicas tornaram-se tema de interesse e cenário de diversas práticas sociais, modo de mediação de poder e de interesses distintos e, muitas vezes, contraditórios, que se encontram em disputa na sociedade civil e política. Sucintamente, apresentamos os estudos de 
implementação e de análise de políticas que podem contribuir como ferramentas importantes de trabalho para todas as áreas que atuam direta ou indiretamente no nível operacional de programas, projetos e políticas públicas e, especialmente, para a Psicologia. Da mesma forma, o saber e as práticas da Psicologia podem e devem contribuir com a discussão da agenda política, com a elaboração, implementação e avaliação das políticas públicas.

Para finalizarmos, gostaríamos de tecer algumas considerações sobre a atuação da Psicologia no campo das políticas públicas, ressaltando como essa área tem contribuido para o processo de implementação das políticas, ao mesmo tempo em que objetiva seu compromisso social por meio de diversas ações, que vão desde a elaboração de subsídios para políticas públicas, como na sua participação na defesa de direitos na Constituição de 1988 e na criação do Estatudo da Criança e do Adolescente, até as práticas profissionais e de controle social das políticas públicas, como podemos acompanhar pelas ações do CFP e dos CRPs, nos Conselhos nacionais, estaduais e municipais de políticas públicas, e, fundamentalmente, na investigação e na produção de conhecimentos.

A Psicologia tem demonstrado historicamente seu compromisso social atuando no debate e na constituição das políticas públicas, seguindo seu percurso de modo a aprofundar as relações e as análises sobre o universo das políticas de forma crítica, sem transformar o sujeito de suas práticas em objeto, o que é muito comum nos discursos administrativos modernos e na burocracia tecnicista das instituições estatais e da sociedade civil. De modo contrário, a Psicologia contribui efetivamente ao garantir um lugar para a subjetividade ser debatida e pensada, no processo de implementação de uma política, ou seja, a essência de sua ação reside justamente na defesa e no resgate desse sujeito do direito, ponto instituído pela modernidade e para o qual se dirigem tanto as práticas psi quanto as ações das políticas sociais.

Isso significa que a Psicologia, ao contribuir com a implementação das políticas públicas, também deve interrogar-se sobre a interferência de padrões culturais de comportamento político bem como sobre suas características, tais como o patrimonialismo, o clientelismo, o privilégio e o favor em detrimento do direito, da dimensão pública e privada e dos direitos coletivos e individuais, que comportam valores historicamente constituídos e arraigados no poder econômico e político brasileiro e que também transpassam as práticas profissionais dos grupos, das organizações e das instituições responsáveis pelo acesso e pela organização de espaços coletivos. Contudo, desvelar tais padrões culturais é alertar para os riscos que cercam as políticas públicas e sua prática social, como a privatização e o neoliberalismo, que podem deslocar a noção histórica de direitos pessoais e coletivos, instituídos na recente ordenação democrática da sociedade brasileira, para antigas relações sociais mediadas pela noção de benevolência, caridade, compaixão ou cooptação ideológica, que reforçam a cultura pautada por relações de dependência, submissão e autoritarismo - matriz consubstancial de políticas impregnadas de paternalismo, clientelismo e populismo, em suma, de uma típica cidadania regulada. Nesse caso, uma nova cultura deve ser construída, conferindo uma qualidade ético-política para as ações do Estado e da sociedade civil, que envolva elementos tais como a socialização de informações e de conhecimentos, a transparência e a prestação de contas à sociedade, a avaliação dos projetos políticos governamentais, o planejamento democrático e participativo, as ações integradas, as consultas públicas e o debate e a atuação junto aos Conselhos 
de políticas, os quais são bons exemplos do caminho em que o Estado e a sociedade devem perseverar para promoverem níveis culturais e políticos mais autônomos e implicados com a constituição subjetiva, individual e coletiva, capaz de representar referências à construção de uma sociedade equitativa e democrática.

No âmbito da atuação da Psicologia, podemos identificar várias ações e atividades que demostram como a área tem contribuído com a implementação de políticas públicas no País. Tais ações e atividades envolvem desde a problematização e o debate de temas na agenda política brasileira, por meio de estratégias de participação e de controle social nos Conselhos de políticas, até a elaboração, execução e avaliação de políticas, programas e projetos. Paralelamente, há um desenvolvimento profícuo de saberes e de subsídios na área, produzidos através de consultas e pesquisas que consideram, além da prática profissional, os cenários e as condições reais de execução das políticas.

A criação e a consolidação do CREPOP, na primeira década do século XXI, tem proporcionado esse debate de modo aberto e participativo, dialogando com a sociedade, com os profissionais e com o poder público, tanto nos âmbitos nacionais, regionais como municipais, por meio da realização de seminários e de consultas públicas além de outras ações existentes em diversos âmbitos. Dito de outro modo, por meio do CREPOP, a Psicologia desenvolve ações coordenadas nacionalmente, que buscam conhecer a realidade a partir da prática dos profissionais, sendo que tal conhecimento tem fomentado novas ações no campo das políticas públicas, como a participação da Psicologia nos Conselhos de políticas públicas e no debate sobre a elaboração e a implementação das políticas sociais, como o SUS, o SUAS e a educação.
Em consonância com as Diretrizes Curriculares Nacionais (2004), o coletivo da Associação Brasileira de Ensino de Psicologia (ABEP), no que concerne à formação de professores e de profissionais de Psicologia, também tem apoiado e defendido a adoção, pelos cursos de graduação, em seus projetos-político pedagógicos, de saberes e de conhecimentos que habilitem o profissional às práticas de Psicologia que envolvam a complexidade da realidade das políticas públicas. Nesse sentido, um exemplo notável são as questões exigidas pelo Exame Nacional do Ensino Superior (ENADE), que passaram a abranger o papel dos direitos sociais na redução das desigualdades sociais e a atuação dos psicólogos em setores específicos de políticas sociais, como o Programa de Atenção Integral à Família (PAIF), do Centro de Referência e Assistência Social (CRAS).

A produção e a publicação de pesquisas e materiais constituem importantes referências para a atuação do profissional de Psicologia no campo das políticas, tornando-se, também, uma ação imprescindível para a área. Dentre tais documentos de referência, destacam-se diversas ações e setores de atuação, tais como: sistema prisional, programas de medidas socioeducativas em meio aberto e internação, programas do idoso, técnicas para prática de Psicologia no CREAS, no serviço de proteção especial à criança e ao adolescente vítimas de violência, abuso e exploração sexual, Varas de Família e subsídios para os gestores da assistência social e para o SUS. Destacam-se, ainda, pesquisas sobre práticas inovadoras na área de segurança e Justiça, direitos humanos, álcool e drogas, DST e AIDS, entre outras, que são socializadas on line.

Desse modo, a psicologia brasileira temse demonstrado um ator imprescindível, objetivando ações para apoiar os profissionais que atuam em diversos setores de políticas públicas e para aprimorar a implementação de políticas sociais e a garantia de direitos, 
problematizando as práticas sociais implicadas, ou que deveriam estar implicadas com as políticas sociais, participando da construção social da realidade e produzindo referências sobre a atuação da Psicologia no campo das políticas públicas. Gonçalves afirma que

Ao se discutir a relação entre Psicologia e direitos humanos, a preocupação é evidenciar como as situações de desrespeito afetam as subjetividades e como o conhecimento psicológico pode servir para a denúncia qualificada e para que, com propriedade, os psicólogos se coloquem na luta pela transformação das situações que acarretam violação dos direitos fundamentais de todos... (2010. p. 101)
Em suma, a Psicologia subsidia o campo das políticas públicas ao problematizar e enfatizar a presença do sujeito e da subjetividade envolvidos em tais fenômenos, ao mesmo tempo em que interroga as concretas condições estruturais envolvidas na constituição das pessoas, do sujeito autônomo, do sujeito histórico, do sujeito humanizado, campo de interesse de todas as áreas que trabalham, direta ou indiretamente, com os processos societários e democráticos. De outro modo, conforme aponta Gonçalves, é imprescindível enfatizar que, "no contexto da discusão e defesa de políticas públicas e da participação da Psicologia nesse campo, os psicólogos deparam com espaços em que se coloca a questão dos direitos humanos" (2010, p. 101). 
Eric Ferdinando Kanai Passone

Doutor em Educação, docente da Faculdade de Psicologia da Universidade Metodista de Piracicaba (UNIMEP) e Pesquisador Associado do Núcleo de Estudos de Políticas Públicas da Universidade Estadual de Campinas (NEPP/ UNICAMP), Campinas - SP - Brasil.

E-mail: eric@nepp.unicamp.br

\section{José Roberto Rus Perez}

Doutor em Educação, Livre Docente da Faculdade de Educação e coordenador do Núcleo de Estudos de Políticas Públicas da Universidade Estadual de Campinas (NEPP/UNICAMP), Campinas - SP - Brasil.

E-mail: rusperez@nepp.unicamp.br

\section{Endereço para envio de correspondência:}

Rua Papa Leão XIII, 10, casa 03, Real Parque. CEP: 13082-793. Campinas, SP.

Recebido 21/11/2011, 1a Reformulação 23/01/2013, Aprovado 11/04/2013.

Arretche, M. T. S. (2003). Dossiê agenda de pesquisas em políticas públicas. Revista Brasileira de Ciências Sociais, 18(51), 7-10.

Brasil. Ministério da Justiça/CBIA/UNICEF (1990). Estatuto da Criança e do Adolescente - ECA. Brasília, DF

Brasil. Presidência da República. Casa Civil (1990, 20 set.). Lei № 8.080, 19 de Setembro de 1990. Dispõe sobre as condições para a promoção, proteção e recuperação da saúde, a organização e o funcionamento dos serviços correspondentes e dá outras providências. Diário Oficial da União.

Brasil. Presidência da República. Casa Civil (1991, 16 out.) Lei № 8.242, de 12 de Outubro de 1991. Cria o Conselho Nacional dos Direitos da Criança e do Adolescente (Conanda) e dá outras providências. Diário Oficial da União.
Brasil. Presidência da República. Casa Civil (1993, 08 dez.). Lei № 8.742, de 07 de Dezembro de 1993. Dispõe sobre a organização da Assistência Social e dá outras providências. Diário Oficial da União.

Brasil. Presidência da República. Casa Civil (1996, 23 dez.). Lei № 9.394, de 20 de Dezembro de 1996. Estabelece as diretrizes e bases da educação nacional. Diário Oficial da União.

Brasil. Ministério do Desenvolvimento Social (2004). PNAS Política Nacional de Assistência Social Brasília, DF.

Brasil. Ministério da Educação. Conselho Nacional da Educação (2004, 12 abr.). Parecer № 0062, de 19 de Fevereiro de 2004. Diretrizes Curriculares Nacionais para os cursos de graduação em Psicologia. Diário Oficial da União. 
Brasil. Presidência da República. Casa Civil (2006, 18 set.). Lei Federal №. 11.346, de 15 de Setembro de 2006. Cria o Sistema Nacional de Segurança Alimentar e Nutricional SISAN com vistas em assegurar o direito humano à alimentação adequada e dá outras providências. Diário Oficial da União.

Carvalho, J. M. (2004). Cidadania no Brasil: o longo caminho (2a. ed.). Rio de Janeiro: Civilização Brasileira.

Cohen, E., \& Franco, R. (2007). Gestão social: como obter eficiência e impacto nas políticas sociais? Brasília, DF: ENAP.

Costa, S. (1999). La esfera pública y las mediaciones entre cultura y política: El caso de Brasil. Metapolítica, 3(9), 95-107.

Dagnino, E. (2004). Sociedade civil, participação e cidadania: de que estamos falando? In D. Mato. Políticas de ciudadanía y sociedad vive en tiempos de globalización (pp. 95-110). Caracas: FACES, Universidad Central de Venezuela.

Dagnino, E., Olvera, A. J., \& Panfichi, A. (Orgs.). (2006). A disputa pela construção democrática na América Latina. São Paulo: Paz e Terra.

Draibe, S. (1997). Uma nova institucionalidade das políticas sociais? Reflexões a propósito da experiência latino-americana recente de reformas e programas sociais. São Paulo em perspectiva, 11, 3-15.

Draibe, S. (1995) Repensando a Política Social: dos Anos 80 ao início dos 90. In L. M., Paulani, L. Sola (Orgs.), Lições da década de 80 (pp. 201-224). São Paulo: Editora da Universidade de São Paulo.

Esping-Andersen, G. (1985). Power and destributional regimes. Politics \& Society, 14(2), 223 - 255.

Faoro, R. (2001). Os donos do poder - formação do patronato político brasileiro. São Paulo: Editora Globo.

Freitas, M. F. Q. (2000). O movimento da lente focal na história recente da psicologia social latino-americana. In R. H. F. Campos \& P. A. Guareschi. (Orgs), Paradigmas em psicologia social - a perspectiva latino-americana (pp. 167-185). São Paulo: Ed. Vozes.

Gonçalves, M. G. M. (2010). Psicologia, subjetividade e políticas públicas. São Paulo: Editora Cortez.

Gonçalves, M. G. M. (2011). Crepop: construção das referências para a atuação dos psicólogos em políticas públicas. In Conselho Federal de Psicologia. V Seminário Nacional Psicologia e Políticas Públicas - Subjetividade, Cidadania e Políticas Públicas. Brasília, DF. Recuperado em 29 outubro, 2012 de http://www.crp13.org.br/CFP/o_estado.pdf

GECD - Grupo de Estudos sobre a Construção Democrática. (1999). Os movimentos sociais e a construção democrática: sociedade civil, espaços públicos e gestão participativa (texto de autoria coletiva). Idéias - Revista do Instituto de Filosofia e Ciências Humanas, 5/6, 43-75.

Hill, H. C. (2006). Language matters: How characteristics of language complicate policy implementation. In M. I. Honnig. New directions in education policy implementation confronting complexity (pp. 65-82). New York: State University of New York Press.

King, D. S. (1988). O Estado e as estruturas sociais de bem-estar em democracias industriais avançadas. Revista Novos Estudos, CEBRAP, 22, 53-76.

Lane, S. T. M. (1984). A psicologia social e uma nova concepção do homem para a Psicologia. In S. T. M. Lane \& W. Codo. Psicologia social: o homem em movimento. São Paulo: Brasiliense.

Lester, J. (1987). Public policy implementation: Evolution of the field and agenda for future research. Policy Studies Review, $7(1), 200-216$.
Lester, J. P., \& Goggin, M. (1998). Back to the future: The rediscovery of implementation studies. Policy Currents, 8(3), $1-9$.

Linder, S. H., \& Peters, B. G. (1987). Relativism, contingency and the definition of sucess in implementation research. Policy Studies Review, 7(1), 116-127.

Marshall, T. (1967). Cidadania, classe social e status. Rio de Janeiro: Zahar

Medeiros, M. (2001). A trajetória do welfare state no Brasil: papel redistributivo das políticas sociais dos anos 1930 aos anos 1990. Texto para discussão №. 852, IPEA, Brasília. Recuperado em 21 junho, 2007 de www.ipea.gov.br/pub/ td/td_2001/td_0852.pdf

Nepp - Núcleo de Estudos de Políticas Públicas (1991). O sistema de proteção social no Brasil. Campinas, SP: Universidade Estadual de Campinas.

Nogueira, M. A. (2003). Sociedade civil - entre o político-estatal e o universo gerencial. Revista Brasileira de Ciências Sociais, 18(52), 187-202.

Nogueira, M. A. (2004). Um estado para a sociedade civil - temas éticos e políticos da gestão democrática. São Paulo: Ed. Cortez.

Orloff, A., \& Skocpol, T. (1984). Why not equal protection? Explaining the politics of public social spending in Britain 1900-1911, and in the United States, 1880s-1920. American Sociological Review, 49, 726-750.

Passone, E. F. K. (2012). Fracasso na implementação de políticas educacionais: uma abordagem pelo discurso psicanalítico. (Tese de Doutorado). Faculdade de Educação, Universidade Estadual de Campinas, Campinas, SP.

Passone, E. F. K. (2007). Políticas sociais de atendimento à infância e juventude: o caso da Fundação Abrinq. (Dissertação de Mestrado em Educação). Universidade Estadual de Campinas, Campinas, SP

Perez, J. R. R. (2010). Por que pesquisar implementação de políticas educacionais atualmente? Educação \& Sociedade, $31,1179-1193$

Perez, J. R. R., \& Passone, E. F. (2010). Políticas sociais de atendimento às crianças e aos adolescentes no Brasil. Cadernos de Pesquisa, 40(140), 649-673. Recuperado em 3 de jul., 2012 de http://educa.fcc.org.br/scielo.php?script=sci_ arttext\&pid $=$ S0100 $>-15742010000200017 \&$ Ing $=$ pt\&nrm $=$ isso.

Pressman, J., \& Wildavsky, A. (1984). Implementation (3rd. ed.). Berkeley: Univ. of California Press.

Saadallah, M. M. (2007). A psicologia frente às políticas sociais. In C. Mayorga \& M. A. M. Prado. (Orgs.), Psicologia social articulando saberes e fazeres (pp. 159-172). Belo Horizonte, MG: Autêntica.

Santos, W. G. (1989). A trágica condição da política social. In S. Abranches et al. (Org.). Política social e combate à pobreza (pp. 33-63). Rio de Janeiro: Jorge Zahar.

Sass, O. (2007). Notas sobre a psicologia social e política no Brasil. In C. Mayorga \& M. A. M. Prado. (Orgs.), Psicologia social articulando saberes e fazeres (pp. 19-36). Belo Horizonte, MG: Autêntica.

Souza, C. (2006, jul/dez). Políticas públicas: uma revisão de literatura. Sociologias, VIII(16), 20-45 